Please do not remove this page

RMIT

UNIVERSITY

\title{
The improvement of a simple theoretical model for the prediction of the sound insulation of double leaf walls
}

Davy, John

https://researchrepository.rmit.edu.au/esploro/outputs/9921863921801341/filesAndLinks?institution=61RMIT_INST\&index=null

Davy, J. (2010). The improvement of a simple theoretical model for the prediction of the sound insulation of double leaf walls. Journal of the Acoustical Society of America, 127(2), 841-849.

https://doi.org/10.1121/1.3273889

Document Version: Accepted Manuscript

Published Version: https://doi.org/10.1121/1.3273889

Repository homepage: https://researchrepository.rmit.edu.au

(c) 2010 Acoustical Society of America

Downloaded On 2023/04/26 22:24:57 +1000 
Davy, J 2010, 'The improvement of a simple theoretical model for the prediction of the sound insulation of double leaf walls', Journal of the Acoustical Society of America, vol. 127, no. 2, pp. 841-849.

\title{
Equation Chapter 1 Section 1
}

The improvement of a simple theoretical model for the prediction of the sound insulation of double leaf walls

\author{
John L. Davy ${ }^{\text {ab }}$
}

School of Applied Sciences, RMIT University, GPO Box 2476V Melbourne, Victoria 3001, Australia

Running title: Sound insulation of double leaf walls

${ }^{a}$ Electronic mail: john.davy@rmit.edu.au .

${ }^{\mathrm{b}}$ Also employed at CSIRO Materials Science and Engineering, PO Box 56 Highett Victoria 3190, Australia. 
This paper presents a revised theory for predicting the sound insulation of double leaf cavity walls that removes an approximation which is usually made when deriving the sound insulation of a double leaf cavity wall above the critical frequencies of the wall leaves due to the airborne transmission across the wall cavity. This revised theory is also used as a correction below the critical frequencies of the wall leaves instead of a correction due to Sewell. It is found necessary to include the "stud" borne transmission of the window frames when modelling wide air gap double glazed windows. A minimum value of stud transmission is introduced for use with resilient connections like steel studs. Empirical equations are derived for predicting the effective sound absorption coefficient of wall cavities without sound absorbing material. The theory is compared with experimental results for double glazed windows and gypsum plasterboard cavity walls with and without sound absorbing material in their cavities. The overall mean, standard deviation, maximum and minimum of the differences between experiment and theory are -0.6 $\mathrm{dB}, 3.1 \mathrm{~dB}, 10.9 \mathrm{~dB}$ at $1250 \mathrm{~Hz}$ and $-14.9 \mathrm{~dB}$ at $160 \mathrm{~Hz}$ respectively.

PACS numbers: 43.55.Rg, 43.55.Ti, 43.40.Rj, 43.20.Rz 


\section{INTRODUCTION}

There are still no really satisfactory theoretical models for predicting the sound insulation of walls. This means that acoustical consultants have to use measured values of sound insulation when designing buildings. Measurements of sound insulation are expensive and time consuming to make. This paper improves the accuracy of a simple theoretical model of sound insulation.

The author (Davy, 1990, 1991, 2009a) derives a theoretical model for the sound transmission of double leaf cavity walls due to the air borne transmission across the wall cavity above the critical frequencies of the cavity wall leaves. In this derivation, the integral over angles of incidence from $0^{\circ}$ to $90^{\circ}$ is approximated by extending the range of integration to $-\infty$ to $\infty$ following the approach of Cremer (1942) for single leaf walls. This extension of range approximation is used to make the integral easier to evaluate analytically. However, it is possible to evaluate the integral analytically without extending the range of integration. Unfortunately, although the principles of integration involved are straight forward, the algebra becomes very messy. In this paper, the integral is evaluated analytically with the assistance of the Maple 11 software package.

The model, developed for use above the critical frequencies of the wall leaves, is also used as a correction below the critical frequencies by assuming that the non-existent critical angle is $90^{\circ}$. This correction replaces Sewell's (1970) correction in the region just below the critical frequencies. This new correction has the advantage that it does not become ill-defined at the critical frequencies of the cavity wall leaves.

When the theory is compared with measurements on double glazed windows it is found that it is necessary to include "stud" borne transmission due to the window frames in order to be able to correctly predict the sound transmission for the wider air gaps. To model steel studs 
correctly, the author's theory (Davy, 1993, 2009a) is extended to include a minimum stud transmission and a value for this quantity is derived by comparison with experimental data.

When there is no sound absorbing material in the wall cavity, this paper derives two empirical linear regression equations for the "effective" sound absorption coefficient of the cavity. One of these equations is for double glazing and the other is for gypsum plaster board cavity walls. Because of approximations made in the author's theory, the "effective" sound absorption coefficient of the cavity is expected to be larger than the actual physical sound absorption coefficient of the cavity.

The theory is compared with experimental results for narrow and wide air gap double glazing and gypsum plaster board cavity walls, both with and without sound absorbing material in the wall cavity. The gypsum plaster board comparison walls include the cases of no structural connection between the wall leaves and steel and wooden studs.

\section{ABOVE THE CRITICAL FREQUENCIES}

Above the lowest of the critical frequencies of the two wall leaves the method given by eqns. (1) to (18) of Davy (2009c) is followed. Because these equations are applied to both wall leaves, the subscript $i=1$ or 2 is applied to the variables $\tau$ (transmission coefficient), $Z$ (bending wave impedance), $m$ (mass per unit area), $\eta$ (total damping loss factor), $\omega_{c}$ (angular critical frequency), $f_{c}$ (critical frequency), $\eta_{\text {int }}$ (internal damping loss factor), $\eta_{\text {rad }}$ (radiation damping loss factor), $a$ (ratio of mass impedance to twice the characteristic impedance of air), and $\theta_{c}$ (coincidence angle). To avoid confusion with a symbol used later on, the variable $r$ (ratio of frequency to critical frequency) is replaced with the variable $\xi$ and the subscript $i$ is also applied to it. Eqn. (2) of Davy (2009c) can also be written as [Cremer (1942) eqn. $(8.19)]$

$$
\tau=2 \int_{0}^{1} \tau(\theta) \sin \theta d(\sin \theta)
$$

Eqn (18) of Davy (2009c) can be written as 


$$
\tau_{i}(\theta)=\frac{1}{s_{i}^{2}} \frac{1}{q_{i}^{2}+\left(x-p_{i}\right)^{2}},
$$

where

$$
\begin{gathered}
p_{i}=1-\frac{1}{\xi_{i}}, \\
s_{i}=\frac{2 a_{i} \xi_{i}}{\sigma\left(\theta_{c i}\right)}, \\
q_{i}=\frac{1+\frac{a_{i} \eta_{i}}{\sigma\left(\theta_{c i}\right)}}{s_{i}}
\end{gathered}
$$

and $\sigma\left(\theta_{c i}\right)$ is the single sided forced radiation efficiency at the coincidence angle of the $i$ th wall leaf. Following the approach of Davy (1990, 1991, 2009c), above the lower of the critical frequencies of each leaf, the sound transmission coefficient $\tau(\theta)$ of a double leaf cavity wall is approximated as

$$
\tau(\theta)=\frac{\tau_{1}(\theta) \tau_{2}(\theta)}{\alpha^{2}}
$$

where $\alpha$ is the sound absorption coefficient of the wall cavity. The reason for adoption of this equation is explained at the end of the next section.

Putting eqn. (6) into eqn. (2) of Davy (2009c) gives the diffuse field sound transmission coefficient as

$$
\tau=\frac{I}{s_{1}^{2} s_{2}^{2} \alpha^{2}}
$$

where $\alpha$ is the sound absorption coefficient of the wall cavity of the double leaf wall and

$$
I=\int_{0}^{1} \frac{d x}{\left[q_{1}^{2}+\left(x-p_{1}\right)^{2}\right]\left[q_{2}^{2}+\left(x-p_{2}\right)^{2}\right]} .
$$


The integral in eqn. (8) can be evaluated using the methods outlined in sections 2.101 to 2.103 of Gradshteyn and Ryzhik (1965). However the algebra is rather complicated. Thus the integral was evaluated with the assistance of the Maple 11 software package.

$$
I=\frac{A+B+C}{D},
$$

where

$$
\begin{gathered}
A=q_{1} q_{2}\left(p_{2}-p_{1}\right) \ln \left\{\frac{\left[q_{1}^{2}+\left(p_{1}-1\right)^{2}\right]\left(q_{2}^{2}+p_{2}^{2}\right)}{\left[\left[q_{2}^{2}+\left(p_{2}-1\right)^{2}\right]\left(q_{1}^{2}+p_{1}^{2}\right)\right.}\right\}, \\
B=q_{1}\left[\left(p_{1}-p_{2}\right)^{2}+q_{1}^{2}-q_{2}^{2}\right]\left[\arctan \left(\frac{p_{2}}{q_{2}}\right)-\arctan \left(\frac{p_{2}-1}{q_{2}}\right)\right], \\
C=q_{2}\left[\left(p_{2}-p_{1}\right)^{2}+q_{2}^{2}-q_{1}^{2}\right]\left[\arctan \left(\frac{p_{1}}{q_{1}}\right)-\arctan \left(\frac{p_{1}-1}{q_{1}}\right)\right], \\
D=q_{1} q_{2}\left[\left(p_{2}-p_{1}\right)^{2}+\left(q_{2}+q_{1}\right)^{2}\right]\left[\left(p_{2}-p_{1}\right)^{2}+\left(q_{2}-q_{1}\right)^{2}\right] .
\end{gathered}
$$

If the two wall leafs have the same properties, $q_{1}=q_{2}=q$ and $p_{1}=p_{2}=p$. This makes eqn. (9) indeterminate. In this situation, eqn. (8) becomes

$$
I=\int_{0}^{1} \frac{d x}{\left[q^{2}+(x-p)^{2}\right]^{2}} .
$$

Evaluating eqn. (14) using the Maple 11 software package gives

$$
I=\frac{q^{2}-p(p-1)}{2 q^{2}\left(q^{2}+p^{2}\right)\left[q^{2}+(p-1)^{2}\right]}+\frac{\arctan \left(\frac{p}{q}\right)-\arctan \left(\frac{p-1}{q}\right)}{2 q^{3}},
$$

where use has been made of the fact that $q>0$ and $p \geq 0$. 
The integrand in eqn. (8) has local maxima when $x=p_{i}$. If $q_{i}<<1$, which is usually the case, and if $\left|p_{1}-p_{2}\right|>>q_{i}$, the integrand is half its local maximum value when $\left|x-p_{i}\right|=q_{i}$. Since $q_{i}$ is usually very much less than 1 , and $p_{i}$ is between zero and one if the frequency is greater than or equal to $f_{c i}$, the values of $x$ where the integrand is significantly different from zero usually lie well inside the integral limits from 0 to 1 . Because of this Davy (1990, 1991, 2009a) approximated the integral in eqn. (8) by extending the limits of integration from minus infinity to plus infinity.

$$
I=\int_{-\infty}^{\infty} \frac{d x}{\left[q_{1}^{2}+\left(x-p_{2}\right)^{2}\right]\left[q_{1}^{2}+\left(x-p_{2}\right)^{2}\right]}
$$

This integral can be evaluated using the calculus of residues. This evaluation was carried out using the Maple 11 software package and gave

$$
I=\frac{\pi\left(q_{1}+q_{2}\right)}{q_{1} q_{2}\left[\left(q_{1}+q_{2}\right)^{2}+\left(p_{1}-p_{2}\right)^{2}\right]} .
$$

If

$$
\frac{a_{i} \eta_{i}}{\sigma\left(\theta_{c i}\right)} \gg 1
$$

which is usually the case, then

$$
q_{i}=\frac{\eta_{i}}{2 \xi_{i}}
$$

Substituting eqns. (17) and (19) into eqn. (7) and evaluating gives

$$
\tau=\frac{\pi \sigma^{2}\left(\theta_{c 1}\right) \sigma^{2}\left(\theta_{c 2}\right)\left(\eta_{1} \xi_{2}+\eta_{2} \xi_{1}\right)}{2 a_{1}^{2} a_{2}^{2} \eta_{1} \eta_{2} \alpha^{2}\left[\left(\eta_{1} \xi_{2}+\eta_{2} \xi_{1}\right)^{2}+4\left(\xi_{1}-\xi_{2}\right)^{2}\right]}
$$

If an infinite wall leaf is assumed, the forced radiation efficiency is given by 


$$
\sigma\left(\theta_{c i}\right)=\frac{1}{\sqrt{1-\frac{1}{\xi_{i}}}}=\frac{1}{\sqrt{1-\frac{\omega_{c i}}{\omega}}}=\frac{1}{\sqrt{1-\frac{f_{c i}}{f}}}=\frac{1}{\cos \theta_{c i}}
$$

Because eqn. (21) gives an infinite result at the critical frequency, a common approximation is to assume that the forced radiation efficiency is unity above the critical frequency. If this assumption is made, eqn. (20) becomes

$$
\tau=\frac{\pi\left(\eta_{1} \xi_{2}+\eta_{2} \xi_{1}\right)}{2 a_{1}^{2} a_{2}^{2} \eta_{1} \eta_{2} \alpha^{2}\left[\left(\eta_{1} \xi_{2}+\eta_{2} \xi_{1}\right)^{2}+4\left(\xi_{1}-\xi_{2}\right)^{2}\right]} .
$$

Eqn. (22) should agree with eqns. (30) to (34) in Davy (1990), eqns. (9) to (13) in Davy (1991) and eqns. (40) to (44) of Davy (2009a). It does not do so for two reasons. The first reason is errors in the older equations. Eqns. (33) in Davy (1990) and (12) in Davy (1991) should read $v=$ $4\left(\xi_{1}-\xi_{2}\right)$ rather than $v=4\left(\eta_{1}-\eta_{2}\right)$. Also the factor $\alpha^{2}$ is missing from the denominator of eqn. (34) of Davy (1990). The second reason is that the approximations made are slightly different. However if the critical frequencies of the two wall leaves are the same, then $\xi_{1}=\xi_{2}=\xi$ and eqn. (22) and eqns. (34) of Davy (1990) (after correction), (13) of Davy (1991) (after correction) and eqn. (44) of Davy (2009a) all reduce to

$$
\tau=\frac{\pi}{2 a_{1}^{2} a_{2}^{2} \eta_{1} \eta_{2} \xi \alpha^{2}\left(\eta_{1}+\eta_{2}\right)} .
$$

It should be noted that the $\xi_{i}$ in Davy (1990), Davy (1991) and Davy (2009a) is the square root of the $\xi_{i}$ used in this paper. If the masses per unity area and the damping loss factors of both wall leaves are the same, then $a_{1}=a_{2}=a$ and $\eta_{1}=\eta_{2}=\eta$ and all four equations reduce further to

$$
\tau=\frac{\pi}{4 a^{4} \eta^{3} \xi \alpha^{2}} .
$$

At the critical frequency of the $i$ th wall leaf, $\xi_{i}=1$ and $p_{i}=0$. This means that one of the maxima of the integrand in eqn. (8) occurs at zero which is the lower limit of integration in eqn. 
(8). Thus the extension of the limits of integration which occurs in eqn. (16) means that this maximum contributes about double to the integral compared to what it did before the extension of the limits of integration. Thus in this paper, eqns. (5), (7) and (9) to (13) or (15) will be used to calculate the sound transmission coefficient instead of the further approximations given by eqns. (17), (19), (20), (22), (23) or (24).

Because eqn. (21) gives an infinite value for the forced radiation efficiency at the critical frequency, this paper uses Davy's (2009a) theory to calculate the forced radiation efficiency. This theory is an updated version of the theory in Davy (2004). First the cosine of the coincidence angle is calculated. Since eqns. (5), (7) and (9) to (13) or (15) are going to be used as a correction term below the critical frequency, the cosine of the coincidence angle is set to zero for frequencies below the critical frequency. The actual equations used are eqns. (33) to (39) of $\operatorname{Davy}(2009 c)$.

To obtain better agreement with experimental results, $\sigma\left(\theta_{c i}\right)$ is set equal to one if the frequency is greater than or equal to the lower of the two critical frequencies. If the frequency is between 0.9 times and 1 times the lower of the two critical frequencies, $\sigma\left(\theta_{c i}\right)$ is linearly interpolated in the frequency domain between the value of $\sigma\left(\theta_{c i}\right)$ at 0.9 times the lower of the two critical frequencies and the value one at the lower of the two critical frequencies.

An alternative approximation is used by Davy (1990, 1991, 2009a). It produces a different result from the approximation used in this paper if the critical frequencies of the two wall leaves are different. This other approximation follows Cremer (1942) and uses eqn. (1) rather than eqn. (2) of Davy (2009c). The $\sin \theta$ term in eqn. (1) is approximated by the average of $\sin \theta_{c 1}$ and $\sin \theta_{c 2}$. This is the approximation that causes the difference if the critical frequencies of the wall leaves are different. It is not needed if eqn. (2) of Davy (2009c) is used but works 
satisfactorily if the critical frequencies are fairly similar. The second $\sin ^{4} \theta$ term in eqn. (12) of Davy (2009c) is approximated as

$$
\sin ^{4} \theta \approx \sin ^{4} \theta_{c i}\left(1+4 \frac{\sin \theta-\sin \theta_{c i}}{\sin \theta_{c i}}\right) .
$$

Then the limits of integration are extended from minus infinity to plus infinity as in eqn. (16). Finally radiation efficiency is approximated to be unity.

\section{BELOW THE CRITICAL FREQUENCIES}

Below the lowest of the critical frequencies of the two wall leaves the method given by eqns. (18) to (35) of Davy (2009a) is followed. An important difference is that a correction factor (Sewell, 1970) for when the critical frequency is approached is omitted from eqn. (24) of Davy (2009a). That is, eqn. (24) of Davy (2009a) becomes

$$
a_{i}=\frac{\omega m_{i}}{2 \rho_{0} c}
$$

where $\rho_{0} c$ is the characteristic impedance of air. Another difference is that the square root of the

panel area $\sqrt{A}$ in eqn. (34) of Davy (2009a) is replaced by the length $2 a$ of the side of an equivalent square panel defined by eqn. (34) of Davy (2009c). Note that this $a$ is different from the $a$ used earlier in this paper. To avoid confusion with symbols used earlier in this paper $p$ is replaced with $P$ and $q$ is replaced with $Q$.

Davy (2009a) uses a variable limiting angle of integration (Sewell, 1970) and shows that the use of this angle for single leaf walls is equivalent to the use of the forced radiation efficiency of the finite size of the wall averaged over all angles of incidence. Thus the use of the variable limiting angle of integration is equivalent to the spatial windowing technique of Villot et al. (2001). For double leaf walls, eqn. (34) of Davy (2009a), which is used in this paper, limits the 
maximum value of the limiting angle of integration to $61^{\circ}$ in order to make the theory agree better with experimental results. Similarly, Schoenwald et al. (2008) found that the spatial windowing technique was not sufficient on its own for double leaf walls and combined it with Kang's (2000) Gaussian distribution of directional incident sound energy.

To compensate for the removal of Sewell's (1970) correction term in eqn. (26), the sound transmission coefficient, above the normal incidence mass-air-mass resonance frequency and below the upper of the two critical frequencies, is calculated as the sum of eqn. (33) of Davy (2009a) and eqn. (7) where eqns. (9) or (15) have been used to evaluate eqn. (7). At and above the upper of the two critical frequencies, only eqn. (7) is used. Eqn. (33) of Davy (2009a) can be included immediately above the upper of the two critical frequencies, but it causes problems if used a long way above both critical frequencies.

$Q$ is half the sum of the ratio of the surface density of one wall leaf to that of the other with the inverse of this ratio. Thus if the wall leaves are the same $Q=1 . P x$ is the product of the ratio of the mass impedance of one wall leaf to twice the specific acoustic impedance of air with the same ratio for the other wall leaf and with the sound absorption coefficient of the cavity and with the square of the cosine of the angle of incidence. Because $Q$ is usually very much less than $P x$, eqn. (28) of Davy (2009a) can be approximated as follows,

$$
\tau(\theta)=\frac{1}{a_{1}^{2} \cos ^{2}(\theta) a_{2}^{2} \cos ^{2}(\theta) \alpha^{2}} .
$$

The first term in the denominator of eqn. (12) of Davy (2009c) is usually very much smaller than the second term. Ignoring this first term, assuming that $\xi_{i}$ is very small and using the value of the radiation efficiency for an infinite panel which is given by eqn. (21) changes eqn. (12) of Davy (2009c) to 


$$
\tau_{i}(\theta)=\frac{1}{a_{i}^{2} \cos ^{2}(\theta)} .
$$

Thus eqn. (27) can be written as eqn. (6). This is the reason for the adoption of eqn. (6).

\section{STUD BORNE TRANSMISSION}

This paper is primarily concerned with air borne transmission across the cavity. However, to the author's surprise, it was found that it was necessary to include "stud borne" transmission between the edges of the glass panes due to the window frames in order to correctly predict the sound insulation of double glazing with larger air gaps. Thus this section gives the formulae for stud borne transmission across the cavity (Davy, 1993, 2009a). The actual equations used are eqns. (47) to (50) of Davy (2009a) where the symbols $D$ (ratio of total to non-resonant radiation) and $g$ (sum of the product of the mass per unit area of each wall leaf with the square root of the angular critical frequency of the other wall leaf) of Davy (2009a) have been replaced with the symbols $H$ and $G$ to avoid confusion with the use of the symbols $D$ and $g$ earlier in this paper. Eqn. (46) of Davy (2009a) is split into the following two equations.

$$
\tau=\frac{32 \rho_{0}^{2} c^{3} H J}{G^{2} b \omega^{2}},
$$

where the stud transmission ratio is

$$
J=\frac{2}{1+\left(1-\frac{4 \omega^{3 / 2} m_{1} m_{2} c C_{M}}{G}\right)^{2}} .
$$

The studs have a mechanical compliance of $C_{M}$ where $C_{M}=0$ gives the rigid stud case. The mechanical compliance of a stud has dimensions of length per (force per length of the stud). The stud transmission $J$ is the ratio of the stud borne sound transmission coefficient for the wall to the stud borne sound transmission coefficient for the same wall with rigid studs $\left(C_{M}=0\right)$. The stud transmission $J$ is restricted to be greater than or equal to the set minimum stud transmission 
K. $C_{M}$ and $K$ are selected to give the best agreement with experiment. This is different from Davy (2009a) which gives the formula for resilient studs but recommends setting the stud compliance to zero and using a set constant stud transmission $J$ for resilient studs instead of the stud transmission $J$ given by eqn. (30). In Davy (2009a), $J$ is selected to give the best agreement with experiment.

Research by Poblet-Puig et al. (2006, 2009), Guigou-Carter et al. (1998) and GuigouCarter and Villot (2006) has shown that a steel stud can be modelled as a translational spring with a translational stiffness which varies with frequency in the range from $10^{5}$ to $10^{8} \mathrm{~Pa}$. The constant value of mechanical compliance used in the next section corresponds to a translational stiffness of $6 \times 10^{5} \mathrm{~Pa}$ which lies towards the bottom end of the above range. The value of the minimum stud transmission used in the next section is $-23 \mathrm{~dB}$. This also lies in the 0 to $-40 \mathrm{~dB}$ stud transmission range determined by Poblet-Puig et al. $(2006,2009)$ for a standard steel stud. It would be possible to use the frequency dependent translational stiffness values determined by Poblet-Puig et al. $(2006,2009)$ with the theory developed in this paper.

$\sigma_{i}$, which appears in eqns (48) and (49) of Davy (2009a), is the single sided radiation efficiency of a free reverberant bending wave vibration field of the $i$ th wall leaf. Note that, below the critical frequency of the $i$ th wall leaf, this is different from the single sided radiation efficiency of a forced bending wave on the $i$ th wall leaf which is given by eqns. (33) to (39) of Davy (2009c). The corrected versions of Maidanik's formulae for the single sided radiation efficiency of a free reverberant bending wave vibration field given by Vér and Holmer (1971) are used in this paper. However the maximum value of the radiation efficiency is limited to the value one. Previous research (Cremer, 1942, Davy, 1993, 2009a) has shown that this assumption works well for predicting the sound transmission of third octave bands of noise above the critical 
frequency. It is also consistent with the restrictions placed on the result of eqns. (33) to (39) of Davy (2009c) above the critical frequency in section II.

The stud borne transmission is not included in the combined transmission below the mass-air-mass resonance frequency. In this frequency range, the wall leaves are already effectively coupled by the air cavity.

\section{COMPARISON WITH EXPERIMENT}

Quantitative measures of the differences between experiment and theory for each of the 7 cases shown in the following figures are given in Table I. This table shows the mean, the standard deviation, the maximum and the minimum in $\mathrm{dB}$. Also shown are the frequencies in $\mathrm{Hz}$ at which the maximum and minimum differences occur. The overall column shows the average of the 7 means, the root mean square of the 7 standard deviations, the maximum of the 7 maxima and the minimum of the 7 minima. In figs. 2 and 3, only the combined theoretical results are used for the calculations whose results are shown in Table 1.

The first comparison is for the case where there is no vibration connection between the two leaves of the wall (except possibly at the edges) and hence only air borne cavity wall transmission is involved. In this first comparison there is sound absorbing material in the wall cavity. The value one is used for the cavity sound absorption coefficient for cavity walls with sound absorbing material in the cavity in this paper, since the experimental results show little dependence of sound insulation on the type or the thickness of the sound absorbing material in the cavity, providing that the sound absorbing material is not too thin or lightweight.

Fig. 1 compares theory with experimental results for five $40 \mathrm{~mm}$ double steel stud $16 \mathrm{~mm}$ gypsum plaster board cavity walls with cavity absorption. There is a $10 \mathrm{~mm}$ gap between the separate studs. The double studs are spaced on $610 \mathrm{~mm}$ centres. The experimental results in fig. 
1 were measured by the National Research Council of Canada (NRCC). The last of the walls measured (TL-92-975) had no studs. The gypsum plaster board is assumed to have a density of $770 \mathrm{~kg} / \mathrm{m}^{3}$, a Young's modulus of $1.85 \times 10^{9} \mathrm{~Pa}$, a Poisson's ratio of 0.3 and an internal damping loss factor of 0.03 . The agreement between theory and experimental is good. Fig. 1 should be compared with fig. 3 of Davy (2009a) where the same experimental data is presented. Slight differences in the two theories can be seen in the frequency region around the peak below the critical frequency.

To determine the appropriate value of the "sound absorption coefficient" to be used to predict the sound insulation of cavity walls without sound absorbing material in the cavity, the NRCC measurements on double glazed windows (Quirt, 1981 and 1982) were analysed. It soon became apparent that it was necessary to include "stud borne" transmission between the edges of the glass panes due to the window frames in order to correctly predict the sound insulation of double glazing with larger air gaps. This is the reason for the inclusion of section IV in this paper. The window size is 2.02 by $1.8 \mathrm{~m}$. The frame has two vertical dividers. Thus each layer of glass consists of three separate panes of glass. This gives a stud spacing of $b=2.02 / 3=0.67 \mathrm{~m}$. The theoretical calculations assume that the density is $2500 \mathrm{~kg} / \mathrm{m}^{3}$, the Young's modulus is $6.5 \times 10^{10} \mathrm{~Pa}$ and Poisson's ratio is 0.22 . The "stud" compliance $C_{M}$ of the window frames is assumed to be $0 \mathrm{~Pa}^{-1}$.

The "sound absorption coefficient" of the cavity and the internal damping loss factor of the glass panes were assumed to be constant as functions of frequency. They were adjusted to provide the best fit between theory and experiment for each of the double glazing combinations that were tested. The "sound absorption coefficient" $\alpha$ of the cavity increased with increasing 
cavity width $d$. A linear regression of the "sound absorption coefficient" as a function of cavity width produced the following equation.

$$
\alpha=0.027+2.4 d
$$

Note that the value of the "sound absorption coefficient" is limited by eqn. (35) of Davy 2009a. Because the second term on the right hand side of eqn. (27) of Davy (2009a) has been ignored, the effective "sound absorption coefficient" $\alpha$ of the cavity is expected to be considerably larger than the actual physical sound absorption coefficient of the cavity. Eqn. (31) is less accurate at larger cavity widths because, as will be seen, the "stud borne" transmission across the window air cavity is dominant in the theoretical values for larger cavity widths.

The average value of the internal damping loss factor of the glass panes was 0.064 . Although this internal damping loss factor seems high for glass, it should be noted that Cremer (1942) assumed a damping loss factor of 0.1 for glass. This internal damping loss factor actually includes the loss of vibrational energy at the edges of the glass panes.

The narrowest window air cavity gap measured by NRCC was $3 \mathrm{~mm}$. Fig. 2 shows a comparison of the air borne, stud borne and combined theoretical results with the experimental result for a double glazed unit consisting of a $3 \mathrm{~mm}$ glass pane, a $3 \mathrm{~mm}$ air gap and another $3 \mathrm{~mm}$ glass pane. Fig. 2 shows that the theoretical sound insulation is controlled by the air borne transmission across the cavity. Remember that the theoretical stud borne transmission is not used below the mass-air-mass resonance which occurs at about $550 \mathrm{~Hz}$ in this situation. The theory under estimates the experimental sound reduction index below $160 \mathrm{~Hz}$ and from 2500 to 4000 Hz. The agreement is good in the other frequency ranges. The under estimation in the 2500 to $4000 \mathrm{~Hz}$ range can be removed by increasing the apparent "sound absorption coefficient" in this frequency range. 
The next comparison shows the case where the two "wall leaves" are different and where the window air cavity gap is large. Fig. 3 compares the air borne, stud borne and combined theoretical results with the experimental result for a double glazed window consisting of $4 \mathrm{~mm}$ and $6 \mathrm{~mm}$ glass panes separated by an air cavity of $100 \mathrm{~mm}$ width. Fig. 3 shows that the theoretical sound insulation is controlled by the stud borne transmission across the cavity above $160 \mathrm{~Hz}$ and by the airborne transmission across the cavity below $160 \mathrm{~Hz}$. The combined theoretical results agree reasonably well with the experimental results, although the theory fails to predict the local maxima at 160 and $200 \mathrm{~Hz}$.

To estimate the stud mechanical compliance $C_{M}$ and the minimum stud transmission $K$ for use in the case of steel studs, test data was taken for five walls from Halliwell et al. (1998). All five walls consisted of two layers of $16 \mathrm{~mm}$ gypsum plaster board mounted on each side of $90 \mathrm{~mm}$ steel studs at $406 \mathrm{~mm}$ centres. All five walls had $90 \mathrm{~mm}$ of porous sound absorbing material in the wall cavity. The first wall had sprayed cellulose fibre, while the second and third walls had glass fibre and the last two walls had mineral fibre. The best fit to the experimental data is obtained by setting the stud mechanical compliance $C_{M}$ equal to $1.6 \times 10^{-6} \mathrm{~Pa}^{-1}$ and the minimum stud transmission $K$ equal to $0.005^{1}$.

The gypsum plaster board is assumed to have a density of $770 \mathrm{~kg} / \mathrm{m}^{3}$ and a Poisson's ratio of 0.3 . To ensure that the two layers of $16 \mathrm{~mm}$ gypsum plaster board have the same critical frequency as a single layer of $16 \mathrm{~mm}$ gypsum plaster board, the Young's modulus is set equal to one quarter of the $1.85 \times 10^{9} \mathrm{~Pa}$ used for a single $16 \mathrm{~mm}$ layer of gypsum plaster board. To obtain good agreement above the critical frequency, the internal damping loss factor is set to 0.02 . The comparison of theory with experiment is shown in fig. 4 . The theory overestimates at $100 \mathrm{~Hz}$ and in the 1000 to $2000 \mathrm{~Hz}$ range. The agreement is good at other frequencies. 
The next comparison is for gypsum plaster board cavity walls without cavity absorption. The last three experimental results in fig. 5 (TL-92-265 through TL-92-267) are for the same construction as the results in fig. 1, except that there is no sound absorbing material in the cavity. In the first three experimental results (TL-92-262 through TL-92-264), the double $40 \mathrm{~mm}$ steel studs with a $10 \mathrm{~mm}$ gap are replaced with $90 \mathrm{~mm}$ steel studs on $813 \mathrm{~mm}$ centres. These $90 \mathrm{~mm}$ steel stud results have been included, because surprisingly they are as good as or better than the double $40 \mathrm{~mm}$ steel stud results. The theoretical curve includes stud borne transmission, but the theoretical stud borne transmission only has a small effect on the total theoretical sound insulation in the region of $100 \mathrm{~Hz}$. Another experimental result for the case with no studs, which is not included here, produced lower results. Presumably this is because the studs help inhibit the oblique propagation of sound in the cavity in this case without sound absorption in the cavity. The experimental measurements in fig. 5 were also measured by the National Research Council of Canada (NRCC).

The original intention was to use eqn. (31) to predict the cavity absorption coefficient. However, comparison with the experimental results shown in this figure, and the results without cavity absorption from Halliwell et al. (1998) and from NAHB (1971), produced the following eqn.

$$
\alpha=0.043+0.73 d .
$$

The mean value of the damping loss factor was 0.044 . This value of the damping loss factor and the value of sound absorption coefficient given by eqn. (32) were used for the theoretical calculations in figs. 5 and 7. The theory in fig. 5 under estimates the experimental results in the range from $500 \mathrm{~Hz}$ to $1600 \mathrm{~Hz}$. Use of eqn. (31) instead of eqn. (32) does a better job of predicting the peak in this range at the expense of over estimating in the range from 160 to 630 
Hz. Fig. 5 should be compared to Fig. 4 of Davy (2009a) where the same experimental data is plotted. The theory of Davy (2009a) is closer to the experimental results in the frequency range from 500 to $1600 \mathrm{~Hz}$. The theory of this paper is closer to the experimental results in the 250 to $400 \mathrm{~Hz}$ range and at $2000 \mathrm{~Hz}$.

Fig. 6 compares theory and experiment for the sound insulation of three $90 \mathrm{~mm}$ wooden stud $16 \mathrm{~mm}$ gypsum plaster board cavity walls with cavity absorption. The stud spacing is 406 $\mathrm{mm}$. The first two experimental results are a new and an old measurement by the National Research Council of Canada (Halliwell et al., 1998 and Northwood, 1968). The third experimental measurement is by Owens/Corning Fibreglas (DuPree, 1981). The second and third experimental results also appear as an average in NAHB (1971). In order to obtain reasonable agreement above the critical frequency, the damping loss factor used to obtain the theoretical result had to be increased to 0.1 .

The theory does not do a good job of predicting the experiment results below $250 \mathrm{~Hz}$. Between 315 and $1250 \mathrm{~Hz}$ it is in reasonable agreement with the most recent measurement, but over predicts the two older measurements. It over predicts between 1600 and $2500 \mathrm{~Hz}$. It is in very rough agreement with the experimental results above $2500 \mathrm{~Hz}$, but only because of the adoption of a theoretical damping loss factor of 0.1 .

Note that the predicted mass-air-mass resonance frequency of about $80 \mathrm{~Hz}$ is significantly less than the measured mass-air-mass resonance frequencies of 125 or $160 \mathrm{~Hz}$. This may be due to a structural resonance which is not included in the theory described in this paper. Bradley and Birta (2001) have shown that the sound insulation of wood stud exterior walls can be significantly degraded by a structural resonance if the two wall leaves are rigidly coupled by the wooden studs. They explain this structural resonance in terms of the analysis conducted by Lin 
and Garrelick (1977). The effects of this resonance can be reduced by structurally isolating the two wall leaves with resilient mounts, thin steel studs, staggered studs or double studs. The frequency of the resonance is about double the calculated mass-air-mass resonance and it reduces in frequency as the rigid stud spacing is increased and as the depth of the rigid studs is increased.

Bradley and Birta (2000) report the results of laboratory sound insulation measurements on typical Canadian building facades. These measurements showed the structural resonance at 125 Hz. However field measurements (Bradley et al. (2001), Bradley (2002)) with actual aircraft noise showed little effect due to this structural resonance.

Fig. 7 compares theory and experiment for $13 \mathrm{~mm}$ gypsum plaster board on each side of $90 \mathrm{~mm}$ thick wooden studs with no sound absorbing material in the wall cavity. The studs are spaced at $400 \mathrm{~mm}$ centres. The experimental results are the average results of two separate experimental measurements (NAHB, 1971). Although the theory over estimates the experimental results below $1000 \mathrm{~Hz}$, it still does a reasonable job of predicting the general trend of the experimental data. The predicted results would compare better with the experimental ones if the value of the cavity absorption coefficient was modified. However, in order to have a prediction method, the cavity absorption given by the linear regression eqn. (32) has been used.

\section{CONCLUSIONS}

A simple theory for predicting the sound insulation of double leaf cavity walls has been revised. An approximation to the range of integration over angle of incidence for the theory above the critical frequency is removed. This enables the theory for above the critical frequency to be used as a correction to theory for below the critical frequency instead of Sewell's (1970) correction and thus gives continuous sound insulation values. The "stud" borne transmission via the window frames is included when modelling the sound insulation of double glazed windows. 
This "stud" borne transmission via the window frames is particularly important for windows with wide air gaps. Linear regression equations for the "effective" sound absorption coefficient of a wall cavity without sound absorbing material in the wall cavity as a function of cavity width are derived for both double glazed widows and gypsum plaster board cavity walls. This "effective" sound absorption increases with increasing wall cavity width.

Comparison with experiment shows that the theory does a reasonably good job of predicting the general trend of the experimental values. The overall mean, standard deviation, maximum and minimum of the differences between experiment and theory are $-0.6 \mathrm{~dB}, 3.1 \mathrm{~dB}$, $10.9 \mathrm{~dB}$ at $1250 \mathrm{~Hz}$ and $-14.9 \mathrm{~dB}$ at $160 \mathrm{~Hz}$ respectively. The theory struggles most when attempting to predict the sound insulation of double leaf gypsum plasterboard walls without sound absorbing material in the wall cavity. This indicates that the assumption that the cavity sound absorption coefficient is constant with frequency, except at low frequencies, probably needs to be revised.

\section{ENDNOTE}

1. It should be noted that the value of the stud mechanical compliance $C_{M}$ is similar to the value

of $1 \times 10^{-6} \mathrm{~Pa}^{-1}$ used by Davy (1990). The minimum stud transmission $K$ is not needed in Davy (1990) because the theoretical airborne transmission across the cavity is greater in that paper because the limiting angle $\theta_{l}$ is not limited to a maximum value of $61^{\circ}$.

\section{REFERENCES}

Bradley, J. S. (2002). IBANA-Calc validation studies (Institute for Research in Construction Research Report, IRC RR-125, National Research Council of Canada, Ottawa, Canada.) 
Bradley, J. S., and Birta, J. A. (2000). Laboratory measurements of the sound insulation of building façade elements (Institute for Research in Construction Internal Report, IRC IR-818, National Research Council of Canada, Ottawa, Canada).

Bradley, J. S., and Birta, J. A. (2001). "On the sound insulation of wood stud exterior walls," J. Acoust. Soc. Am. 110, 3086-3096.

Bradley, J. S., Lay, K., and Norcross, S. G. (2001). Measurements of the sound insulation of a wood framed house exposed to aircraft noise (Institute for Research in Construction Internal Report, IRC IR-831, National Research Council of Canada, Ottawa, Canada, revised 2002).

Cremer, L. (1942). "Theorie der Schalldämmung Wände bei schrägem Einfall (Theory of the sound attenuation of thin walls with oblique incidence)," Akustische Zeitschrift 7, 81-104. Most of this article has been republished with an English language summary in: Northwood, T. D. (1977). "Theory of the sound attenuation of thin walls with oblique incidence" in: Architectural Acoustics, edited by T. D. Northwood, Benchmark Papers in Acoustics 10 (Dowden, Hutchinson and Ross, Stroudsburg, Pennsylvania, USA), pp. 367-399.

Davy, J. L. (1990). "A model for predicting the sound transmission loss of walls", The Australian Vibration and Noise Conference 1990 (The Institution of Engineers, Australia, Canberra, Australia, National Conference Publication No. 90/9), pages 23-27.

Davy, J. L. (1991). "Predicting the sound insulation of stud walls", The Costs of Noise Proceedings of Inter-Noise 91 Conference, edited by Lawrence, A. (Australian Acoustical Society, Sydney, Australia), Volume 1, pages 251-254.

Davy, J. L. (1993). "The sound transmission of cavity walls due to studs", in: People Versus Noise - Proceedings of the Inter-Noise 93 Conference, edited by Chapelle, P. and Vermeir, G. (Belgium Acoustical Association, Leuven, Belgium), Volume 2, 975-978. 
Davy, J. L. (1998). "Problems in the theoretical prediction of sound insulation", Sound and silence: setting the balance, proceedings of the International Conference on Noise Control Engineering, edited by Goodwin, V. C. and Stevenson, D. C. (New Zealand Acoustical Society Inc., Auckland, New Zealand), paper no. 44.

Davy, J. L. (2004). "The radiation efficiency of finite size flat panels," Gold Coast, November 35, Acoustics 2004, Transportation noise and vibration - The new millennium, Proceedings of the Annual Conference of the Australian Acoustical Society, edited by Mee, M. J., Hooker, R. J. and Hillock, I. D. M., (Book ISBN 909882-21-5, CDROM ISBN 0-909882-22-3 ISSN 1446-0998, published by Australian Acoustical Society, Castlemaine, Victoria, Australia), pages 555-560.

Davy, J. L. (2009a). "Predicting the sound insulation of walls," J. Building Acoustics 16, 1-20.

Davy, J. L. (2009b). "The forced radiation efficiency of finite size flat panels which are excited by incident sound," J. Acoust. Soc. Am. 126, 694-702.

Davy, J.L. (2009c). "Predicting the sound insulation of single leaf walls - extension of Cremer's model," J. Acoust. Soc. Am. 126, 1871-1877.

Dupree, R. B. (1981). Catalog of STC and IIC ratings for wall and floor/ceiling assemblies with TL and ISPL data plots (Office of Noise Control, California Department of Health Services, Berkeley, California, USA).

Gradshteyn, I. S., and Ryzhik, I. M. (1965). Table of integrals, series, and products, Fourth Edition, prepared by Geronimus, Yu. V., and Tseytlin, M. Yu., translated from Russian by Scripta Technica Inc., edited by Jeffrey, A. (Academic Press, New York, USA).

Guigou-Carter, C., Villot, M., and Vernois, L. (1998). "Study of cavity ties for improving efficiency of acoustical lining," Euronoise, Munich, Germany. 
Guigou-Carter, C., and Villot, M. (2006). "Analytical and experimental study of single frame double wall," Euronoise 2006, 30 May - 1 June 2006, Tampere, Finland.

Halliwell, R. E., Nightingale, T. R. T., Warnock, A. C. C., and Birta, J. A. (1998). Gypsum board walls: transmission loss data (Internal Report IRC-IR-761, Institute for Research in Construction, National Research Council of Canada, Ottawa, Canada).

Kang, H.-J. (2000). "Prediction of sound transmission loss through multilayered panels by using Gaussian distribution of directional incident energy,” J. Acoust. Soc. Am. 107, 1413-1420.

Lin, G-F., and Garrelick, J. M. (1977) "Sound transmission through periodically framed parallel plates,” J. Acoust. Soc. Am. 61, 1014-1018.

NAHB (1971). Acoustical manual - apartment and home construction (NAHB Study 210-21, National Association of Home Builders Research Foundation Inc., Rockville, Maryland, USA).

Northwood, T. D. (1968). Transmission loss of plasterboard walls (Building Research Note, BRN-66, Division of Building Research, National Research Council of Canada, Ottawa, Canada).

Poblet-Puig, J., Rodriguez-Ferran, A., Cuigou-Carter, C., and Villot, M. (2006). "Experimental and numerical characterization of metallic studs," Euronoise 2006, 30 May - 1 June 2006, Tampere, Finland.

Poblet-Puig, J., Rodriguez-Ferran, A., Cuigou-Carter, C., and Villot, M. (2009). "The role of studs in the sound transmission of double walls," Acta Acustica united with Acustica 95, 555567.

Quirt, J. D. (1981). Measurements of the sound transmission loss of windows (Building Research Note BRN-172, Division of Building Research, National Research Council of Canada, Ottawa, Canada). 
Quirt, J. D. (1982). "Sound transmission through windows I. Single and double glazing," J. Acoust. Soc. Am. 72, 834-844.

Schoenwald, S., Gerretsen, E., and Martin, H. J. (2008). "Prediction of the sound transmission loss of multilayered small sized elements," on the DVD: Proceedings of Acoustics'08, 29 June-4 July, Paris, France.

Sewell, E. C. (1970). "Transmission of reverberant sound through a single-leaf partition surrounded by an infinite rigid baffle," J. Sound and Vib. 12, 21-32.

Vér, I. L., and Holmer, C. I. (1971). "Chapter 11 Interaction of sound waves with solid structures", Noise and vibration control, edited by Beranek, L. L., (McGraw-Hill, New York, USA) 270-361.

Villot, M., Guigou, C., and Gagliardini, L. (2001). "Predicting the acoustical radiation of finite size multi-layered structures by applying spatial windowing on infinite structures," J. Sound Vib. 245, 433-455. 
TABLE I. This table shows the mean, the standard deviation, the maximum and the minimum in $\mathrm{dB}$ of the differences between experiment and theory for each of the 7 cases presented in the accompanying figures. Also shown are the frequencies in $\mathrm{Hz}$ at which the maximum and minimum differences occur. The overall column shows the average of the 7 means, the root mean square of the 7 standard deviations, the maximum of the 7 maxima and the minimum of the 7 minima. In figs. 2 and 3, only the combined theoretical results are used for the calculations whose results are shown in this table.

\begin{tabular}{|l|l|l|l|l|l|l|l|l|}
\hline & Fig. 1 & Fig. 2 & Fig. 3 & Fig. 4 & Fig. 5 & Fig. 6 & Fig. 7 & Overall \\
\hline Mean (dB) & -0.6 & 1.1 & 1.2 & -2.1 & 0.9 & -3.3 & -1.5 & -0.6 \\
\hline Standard deviation (dB) & 2.4 & 2.7 & 2.7 & 3.1 & 3.9 & 4.3 & 2.3 & 3.1 \\
\hline Maximum (dB) & 3.0 & 7.6 & 8.4 & 4.2 & 10.9 & 8.5 & 2.1 & 10.9 \\
\hline Minimum (dB) & -9.3 & -2.0 & -2.6 & -12.5 & -5.4 & -14.9 & -5.6 & -14.9 \\
\hline Frequency of maximum (Hz) & 200 & 80 & 160 & 50 & 1250 & 80 & 4000 & 1250 \\
\hline Frequency of minimum (Hz) & 2000 & 400 & 80 & 2000 & 315 & 160 & 160 & 160 \\
\hline
\end{tabular}




\section{FIGURE CAPTIONS}

Fig. 1. Comparison of theory and experiment (measured by National Research Council of Canada) for the sound insulation of five double steel stud $16 \mathrm{~mm}$ gypsum plaster board cavity walls with cavity absorption. The cavity width is $90 \mathrm{~mm}$.

Fig. 2. Comparison of the air borne, stud borne and combined theoretical results with the experimental result (Quirt, 1981 and 1982) for the sound insulation of a sealed double glazed unit consisting of two $3 \mathrm{~mm}$ glass panes separated by an air cavity of $3 \mathrm{~mm}$ width.

Fig. 3. Comparison of the air borne, stud borne and combined theoretical results with the experimental result (Quirt, 1981 and 1982) for the sound insulation of a double glazed window consisting of $4 \mathrm{~mm}$ and $6 \mathrm{~mm}$ glass panes separated by an air cavity of $100 \mathrm{~mm}$ width.

Fig. 4. Comparison of theory and experiment (Halliwell et al., 1998) for the sound insulation of five $90 \mathrm{~mm}$ steel stud cavity walls with cavity absorption. Each side of the steel studs has two layers of $16 \mathrm{~mm}$ gypsum plaster board attached.

Fig. 5. Comparison of theory and experiment (measured by National Research Council of Canada) for the sound insulation of three steel stud and three double steel stud $16 \mathrm{~mm}$ gypsum plaster board cavity walls without cavity absorption. The cavity width is $90 \mathrm{~mm}$.

Fig. 6. Comparison of theory and experiment (Halliwell et al., 1998, Northwood, 1968 and DuPree, 1981) for the sound insulation of three $90 \mathrm{~mm}$ wooden stud $16 \mathrm{~mm}$ gypsum plaster board cavity walls with cavity absorption.

Fig. 7. Comparison of theory and experiment (NAHB, 1971) for the sound insulation of a $13 \mathrm{~mm}$ gypsum plaster board $90 \mathrm{~mm}$ cavity wall without cavity absorption. 


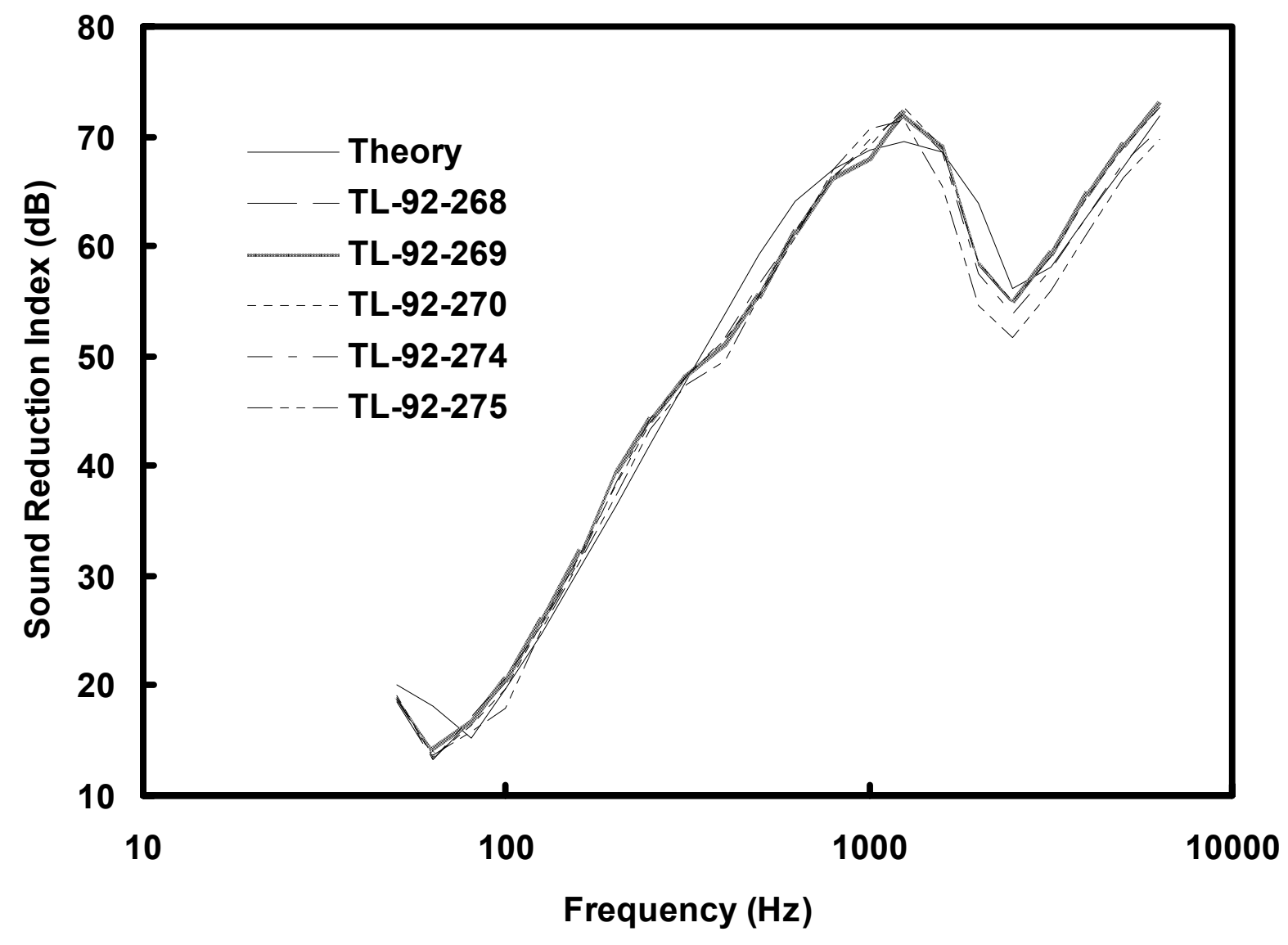




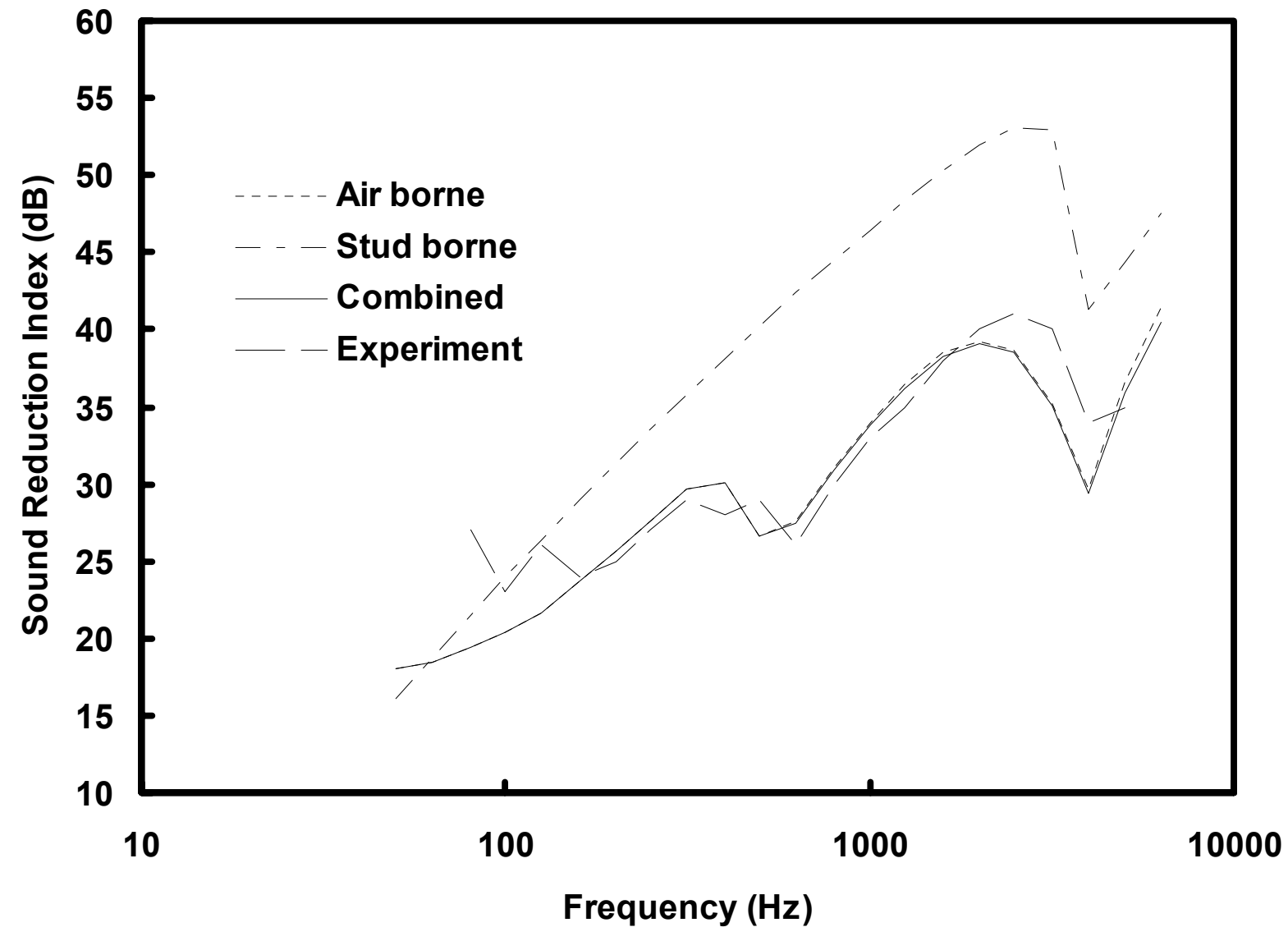




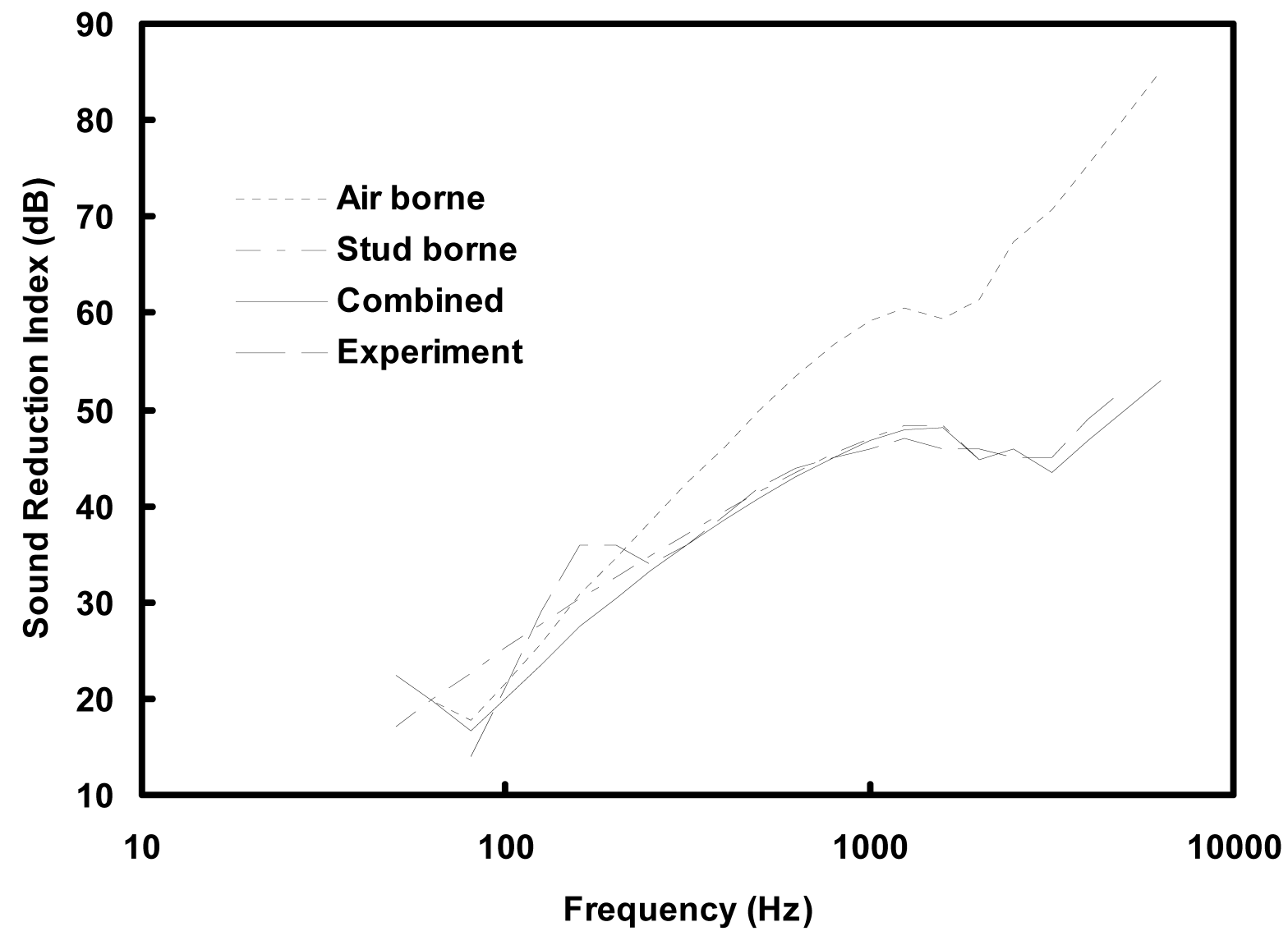




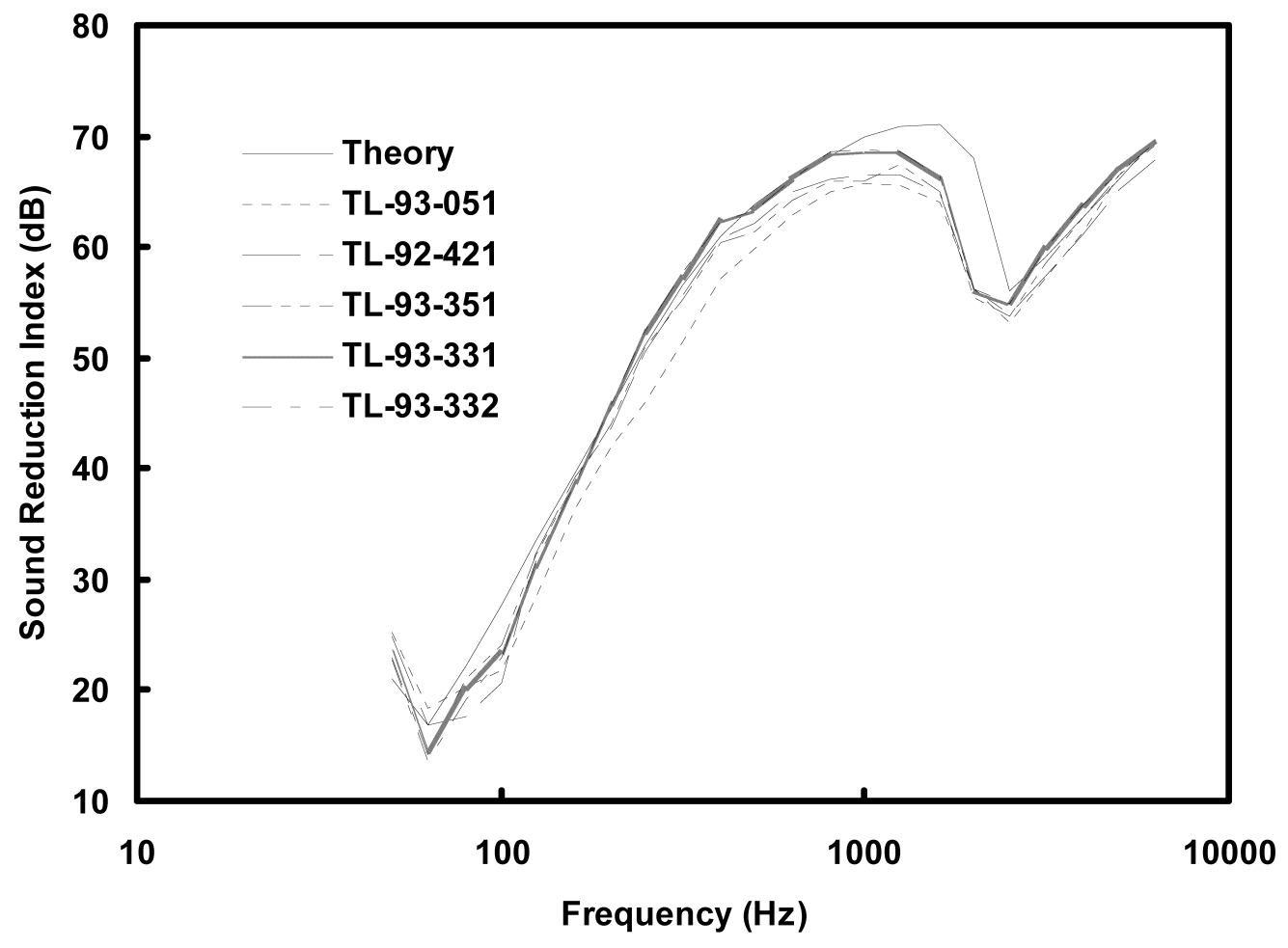




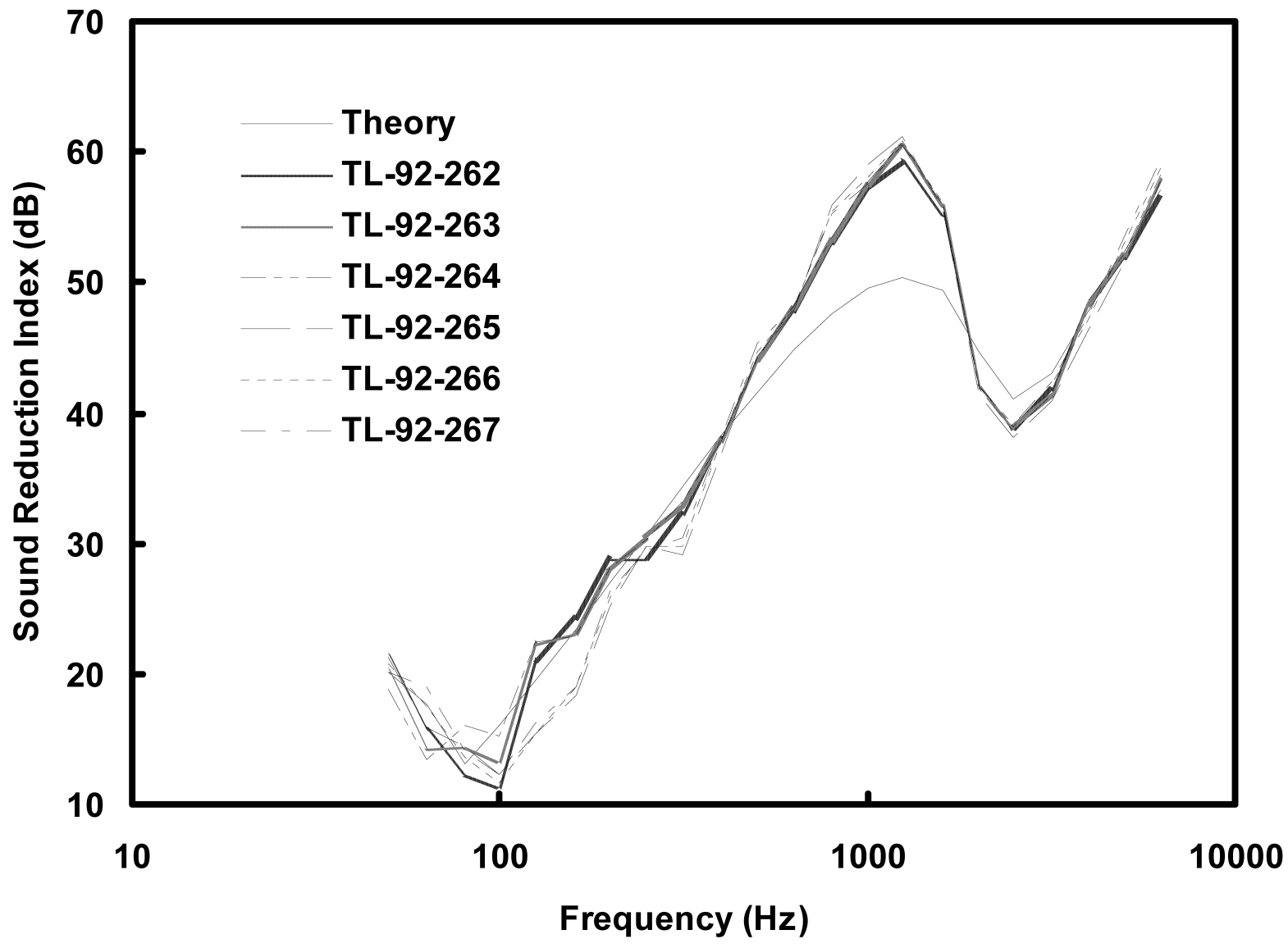




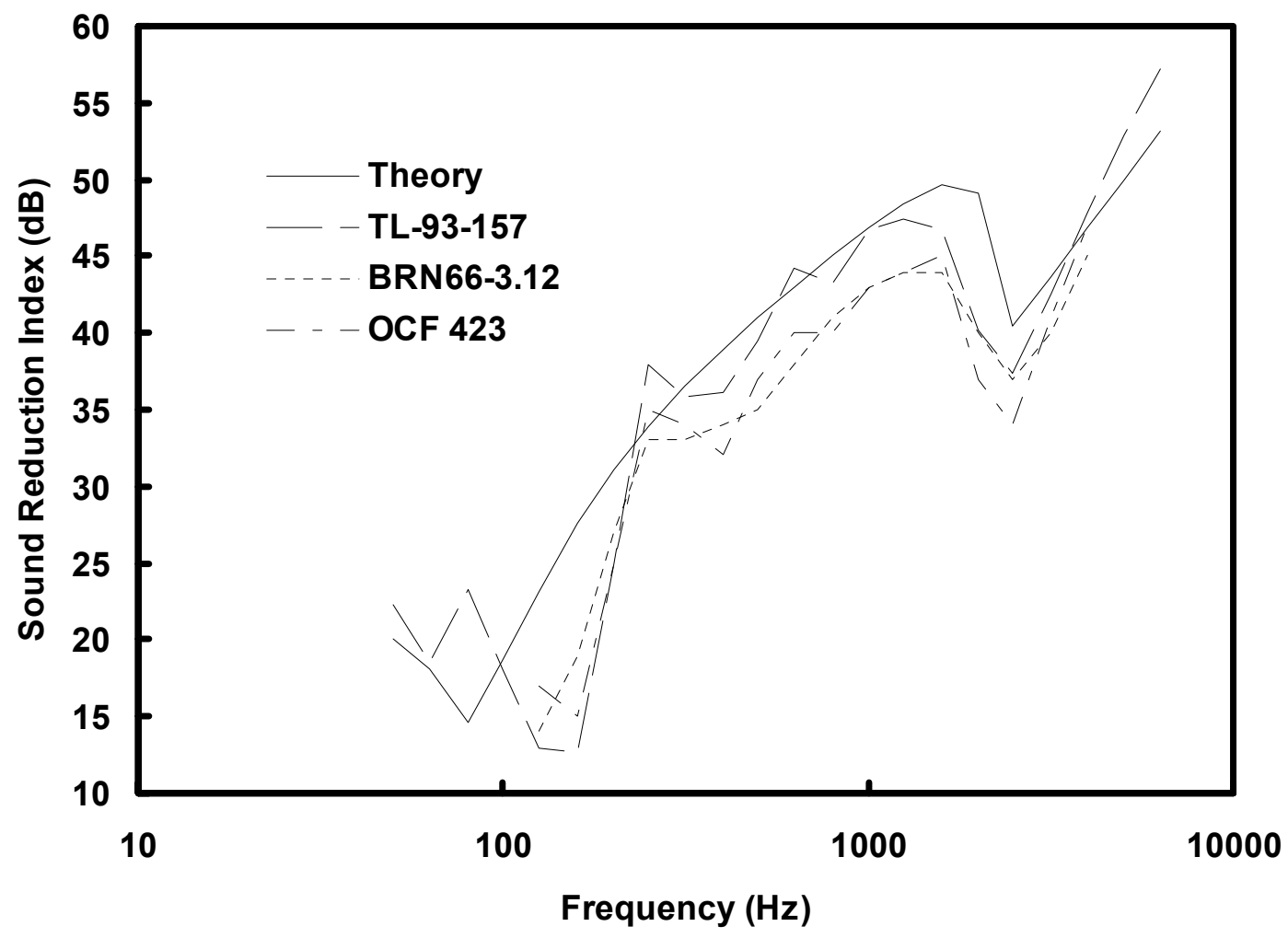




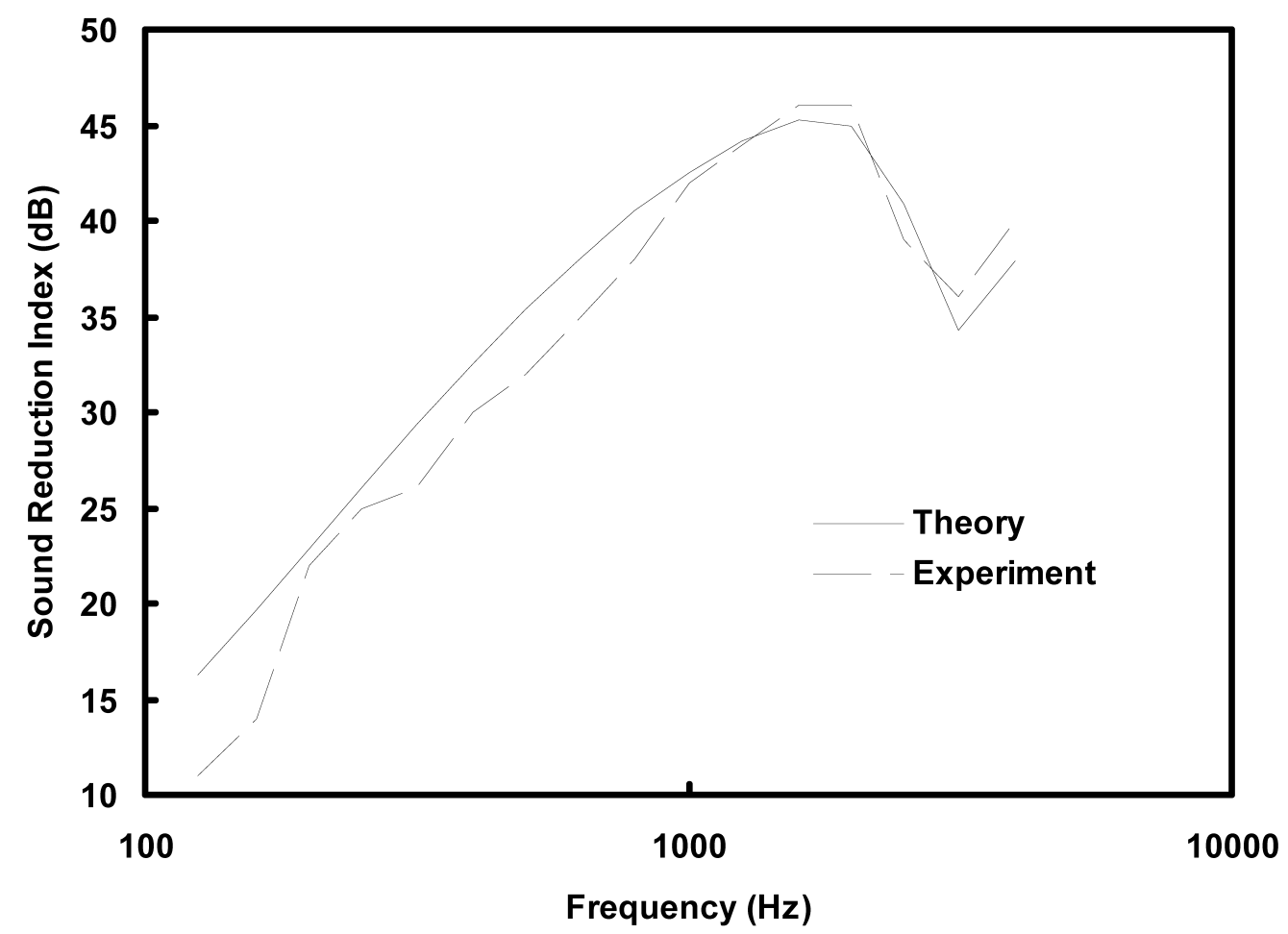

